\title{
New and emerging treatment approaches to lupus
}

\author{
This article was published in the following Dove Press journal: \\ Biologics:Targets \& Therapy \\ 4 September 2010 \\ Number of times this article has been viewed
}

\section{Marion Haubitz \\ Department of Nephrology, Medical School Hannover, Hanover, Germany}

Correspondence: Marion Haubitz Department of Nephrology, Medical School Hannover, Carl-Neuberg-Str. I 30625 Hannover, Germany

Phone +495115326319

Fax +49 5II 5328108

Email haubitz.marion@mh-hannover.de
Abstract: The main goal in systemic lupus erythematosus (SLE) is to achieve remission, as this has a major impact on patient and renal survival. Furthermore, early treatment success has been shown to improve long-term prognosis. Treatment in severe SLE, especially in lupus nephritis, has traditionally been a standardized schematic therapy with cyclophosphamide and prednisolone followed by azathioprine. However, animal and human studies have increased our pathogenetic knowledge of this autoimmune disease with emerging new treatment targets. New and future therapeutic approaches are focused on B-cell depletion, T-cell downregulation and co-stimulatory blockade, cytokine inhibition, or the modulation of complement. Many different biological agents have been used in recent and ongoing studies, but up to now breakthroughs emerging from randomized Phase III trials have been rare. However, the future remains exciting with progress towards safe treatments with which to control the disease in the long run.

Keywords: systemic lupus erythematosus, lupus nephritis, B-cell depletion, co-stimulatory blockade, cytokine inhibition, monoclonal antibodies

\section{Introduction}

Systemic lupus erythematosus (SLE) is a typical autoimmune disease that affects many different organs and is characterized by numerous autoantibodies. In the clinical course of the disease flares are frequently observed, with disease activity in different organs leading to increasing disability and organ damage. Treatment has included the use of corticosteroids, chloroquine, azathioprine, and cyclophosphamide, and in the last decades the prognosis has markedly improved. The 5-year survival of patients with lupus nephritis has exceeded $90 \% .{ }^{1}$ Nevertheless morbidity, especially renal failure, and mortality from active disease or infections initially, and cardiovascular events later on, are still an important issue. ${ }^{2,3}$ In the last decade new treatment strategies have been developed, while others are just emerging. Many of the new therapeutic approaches have been generated taking into account the pathogenesis of the disease. Autoantibodies against nuclear, cytoplasmic, and membrane antigens play an important pathogenetic role. Beside autoantibody production, B-cells are the key for the activation of the immune system, particularly through cytokines and as antigen-presenting cells. An important part of B-cells are activated in a T-cell dependant manner. This knowledge, and other insights from animal models, have been the driving force for the development of new drugs for patients with different forms of SLE.

This article will focus especially on biologicals acting on B-cell and T-cell receptors, cytokines, or complement but will also mention new combinations or applications of known drugs. 
The main goal of the therapy for systemic lupus erythematosus, and especially for lupus nephritis is to achieve and maintain remission, as this has a major impact on patient and renal survival. ${ }^{4,5}$ Traditionally this has been achieved with cyclophosphamide (in combination with steroids), but data, especially from Chinese and AfricanAmericans, give the impression that mycophenolate mofetil (MMF) is more effective, and causes fewer adverse events than cyclophosphamide. ${ }^{6,7}$ However, in a larger randomized study superiority of MMF could not be shown, ${ }^{8}$ and more patients on MMF died, but the difference was not significant. The higher susceptibility to toxic side effects of MMF might be due to a high MMF dose and a special genetic background. The advantage of probable lower long-term side effects remains, ${ }^{9}$ however long-term data regarding MMF in lupus nephritis are missing. MMF acts mainly on activated lymphocytes, but also interferes with antibody production, limits the immune cell-cell interaction by influencing adhesion molecule expression, and affects dendritic cells, which are responsible for activating naïve T-cells. This points to the fact that the key for effective new treatments lies in the pathogenesis of the disease, the role of B-cells and T-cells, as well as the co-stimulatory molecules (CD40/CD40 ligand, CD28/B7), cytokines and other factors involved. Important targets and the treatment approaches are shown in Figure 1 and Table 1.

\section{B-cell target}

Despite the fact that the pathogenesis of the disease has not yet been fully defined there is no doubt on the central role of B-cells at multiple levels as shown by research in mice and humans. Autoantibody production leads to the formation of immune complexes resulting in an inflammatory reaction, stimulates toll-like receptors and influences cytokine production like interleukin-1 (IL-1), IL-2, tumor necrosis factor (TNF) and interferon- $\alpha$ (IFN- $\alpha$ ) via innate immune cells. Antibody-independent B-cell functions include T-cell activation, antigen presentation and effects on dendritic cells.

\section{Rituximab}

Therefore B-cell depletion is an attractive approach. The first B-cell depleting biological was rituximab, a mouse-human chimeric monoclonal antibody against $\mathrm{CD} 20$ which is found on the surface of pre-B-cells and mature B-cells, but not on plasma cells, leaving them unaffected by the treatment. Rituximab was the first monoclonal antibody approved by the Food and Drug Administration (FDA) in 1997 for the treatment of lymphoma. It has been successfully used for rheumatoid arthritis. ${ }^{10}$ Whereas the first studies in heterogenous, mostly small SLE groups showed a favourable response in patients with effective B-cell depletion (by cytotoxicity or apoptosis), ${ }^{11}$ other studies could not confirm the results. Two large multicenter randomized placebo-controlled

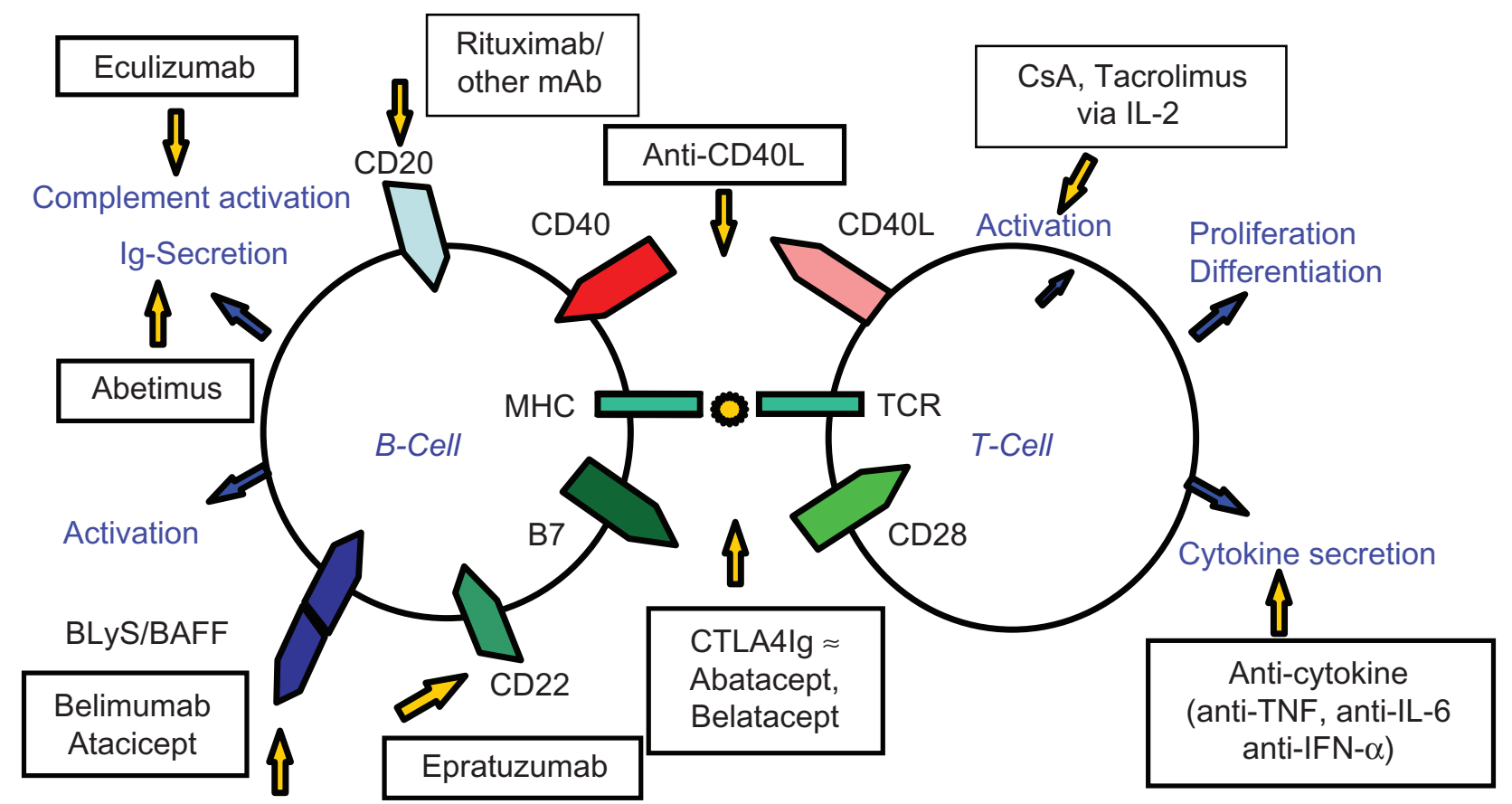

Figure I Potential future targets and relevant drugs in connection with B-cells and T-cells in the management of systemic lupus erythematosus (SLE).

Abbreviations: MHC, major histocompatiability complex; CsA, cyclosporin A; IL-2, interleukin-2; mAb, monocloral antibodies; IFN, interferon; TNF, tumor necrosis factor; BAFF, B-cell activating factor; BLyS, B lymphocyte stimulator. 
trials with rituximab in moderately to severely active SLE (EXPLORER, 257 patients) and in proliferative lupus nephritis patients (LUNAR, 144 patients) could not demonstrate a significant benefit of rituximab. ${ }^{12,13}$ This might be due to an aggressive background treatment and/or to a problematic selection of patients (in a subgroup analysis, African Americans and Hispanics did significantly better on rituximab). Despite the lack of evidence in randomized trials, physicians still tend to use rituximab in refractory patients and report improvement in up to $89 \%$ of the patients, ${ }^{14}$ even histologically. ${ }^{15}$ Whereas in rheumatoid arthritis initially no severe adverse events have been seen, awareness of infectious complication is necessary, and the reactivation of hepatitis as well as the development of progressive multifocal leukoencephalopathy have been reported.

\section{Monoclonal anti-CD20 antibodies}

Several new monoclonal anti-CD20 antibodies have been developed. Ocrelizumab a recombinant humanised monoclonal anti-CD20 antibody has been studied in Phase III trials in extrarenal SLE (BEGIN study) and lupus nephritis (BELONG study) (both at www.ClinicalTrials.gov). Dosing of ocrelizumab has been stopped in trials of SLE, firstly in the BEGIN study following the negative outcome of a similar study design with the anti-CD20 antibody rituximab (see above), and more recently in the BELONG study, due to an imbalance in serious (including opportunistic) infections with ocrelizumab in combination with standard of care (compared to standard of care alone), and following the negative outcome of the rituximab lupus nephritis study (see above). Additionally, dosing was suspended in studies in rheumatoid arthritis due to a higher proportion of serious infections occurring in the ocrelizumab groups compared to placebo.

Further new monoclonal antibodies targeting CD20 have been developed which are fully humanized (ofatumumab and GA-101-R05072759), or $>90 \%$ humanized (veltumumab) ${ }^{16}$ They have mainly been applied to patients with lymphoma or rheumatoid arthritis. No data regarding SLE are available.

\section{Epratuzumab}

Epratuzumab, a recombinant humanized monoclonal anti-CD 22 antibody, has been shown to reduce peripheral B-cells in moderately active SLE patients by $35 \% .{ }^{17}$ A modifying effect on B-cells has been postulated, as ezpratuzumab is nondepleting. CD22 is expressed on pro-B-cells, pre-B-cells, and mature B-cells, and unlike CD20, delivers and modifies intracellular signalling. After positive results in an open-label single-center study on 14 patients, ${ }^{17}$ multicenter randomized trials have been started. In two Phase III trials prematurely discontinued due to drug supply interruption, a clinically meaningful reduction in steroid use was evident, supporting the conduction of further studies. ${ }^{18}$

\section{Abetimus}

Abetimus (LJP 394; Riquent ${ }^{\circledR}$, La Jolla Pharmaceuticals San Diego, CA) consists of four dsDNA epitopes on a polyethylene glycol platform. It cross-links anti-dsDNA surface immunoglobulin receptors on B-cells, leading to anergy or apoptosis. It also reduces titers of anti-dsDNA antibodies. However, used in 14 clinical trials, it failed to show a significant difference in renal flares, including double-blind, placebo-controlled studies in preventing relapses in lupus nephritis. ${ }^{19,20}$ However, post hoc analysis regarding the influence of binding affinity of abetimus to the patients' anti-dsDNA antibodies showed promising results when patients with high affinity antibodies were studied separately. Therefore in another Phase III trial the intention-to-treat population was defined as those with high-affinity antibodies for abetimus. Despite the fact the use of abetimus again led to a significant reduction of anti-dsDNA antibodies, no clinical significant impact could be demonstrated. The last trial was initiated in 2004 (ASPEN trial) with the primary endpoint being "time to renal flare" and in which over 890 patients were enrolled. In February 2009 an interim analysis reported that the trial would not be able to meet the expected endpoint, and the trial was stopped. Up to now no data from the ASPEN trial have been released.

\section{BLyS blockers}

The B cell survival molecule B lymphocyte stimulator (BLyS) also known as B cell activation factor of the TNF family (BAFF) provides a homeostatic signal for B cell survival, differentiation and activation. It therefore represents an excellent target for interventions. High serum levels of soluble BLyS, and its homolog APRIL (a proliferation inducing ligand), are found in patients with SLE; in murine lupus, selective blockade of BLyS reduces transitional type 2 follicular and marginal-zone B-cells, and significantly attenuates immune activation. ${ }^{21}$ In a Phase II double-blind placebo-controlled trial belimumab, a human monoclonal antibody to BLyS which prevents the binding of soluble BLyS to its receptors, failed to meet its endpoints at 24 weeks ${ }^{22}$ but a post hoc analysis by week 52 suggested that belimumab reduces activity and prevents flares. In two Phase III trials (BILISS-52 and BLISS- 76 both with more than 800 patients with moderately 
active disease), the end-points have been met, showing that belimumab plus standard care achieved a significant improvement in patient response rate, and increased time to-first-flare compared with placebo plus standard care (for BLISS-52;23 announcement of GlaxoSmithKline and Human Genome Science for BLISS-76).

An alternative approach to block BlyS is atacicept (known as TACI-Ig). It is a soluble transmembrane activator and calcium-modulator and cyclophilin ligand interactor (TACI) receptor and binds BLyS and APRIL with antagonistic effects. A Phase II/III study in generalized systemic lupus erythematosus with the aim to reduce flares is recruiting; another Phase II/III study in lupus nephritis where atacicept has been added to MMF, with the aim to improve renal response, has been terminated (www.ClinicalTrials.gov).

\section{Other inhibitors}

Targeting costimulatory signalling pathways also affects B-cells, as does inhibition of several cytokines, but both will be described below.

Beside promising results targeting B-cells in autoimmune diseases, many questions have to be answered. One is the search for markers for the response; another is the role of a combined treatment with MMF, cyclophosphamide, and calcineurin inhibitors. An important issue is the question of safety of retreatment and long-term effects.

\section{T-cell target and co-stimulatory blockade}

In addition to the specific recognition of the antigen, lymphocyte activation requires co-stimulatory signals provided by receptor-ligand pairs on $\mathrm{B}$ and T-cells. The inhibition of this interaction has been demonstrated to be effective in murine lupus models. ${ }^{24,25}$ CD28:B7 co-stimulatory interaction was the first described with CD28 expressed on T-cells, whereas the ligands B7-1 and B7-2 (CD80 and CD86) are found on antigen presenting cells. CD28:B7 is the most important antigen-independent signal for T-cell activation. Cytotoxic T-lymphocyte antigen (CTLA4) also interacts with B7 but inhibits T-cell activation. Therefore a fusion protein of CTLA4 and immunoglobulin was constructed (CTLA4-Ig or abatacept and the successor belatacept which differs by only two amino acids) which has a higher affinity to CD28 than B7. After successful application in mice, those biologicals were used in psoriasis and rheumatoid arthritis (abatacept is approved by the FDA for rheumatoid arthritis ${ }^{11}$ ), and to prevent rejection of allografts (belatacept). In patients with SLE, abatacept has been or is being used in trials Phase I to
III. In a Phase II trial with moderately active SLE, abatacept failed to meet both the primary (reduction of SLE flares) and secondary endpoints. ${ }^{26} \mathrm{~A}$ post-hoc analysis however suggests activity of the biological, supporting its further assessment in SLE. Two randomized trials in lupus nephritis with the primary endpoint complete remission are recruiting patients. Abatacept is given in addition to cyclophosphamide (Phase II trial, estimated enrolment 100 patients) or MMF (Phase II/III trial, estimated enrolment 303 patients) (www. ClinicalTrials.gov).

Another important co-stimulatory pair that induces T-cell dependent B-cell proliferation and antibody production is CD40-CD40 ligand. CD40 is expressed on antigen presenting cells and binds to CD40L (or CD154) on CD4+ T helper cells. CD40L is over-expressed in T helper cells of SLE patients ${ }^{16}$ and $\mathrm{SCD} 40 \mathrm{~L}$ is elevated in the serum of patients. After very encouraging results in mice with lupus nephritis two different monoclonal antiCD40L antibodies were used in humans. In a Phase II trial IDEC-131 demonstrated no improvement compared to placebo. ${ }^{27}$ In a study in patients with proliferative lupus nephritis using BG9588, the antibody seemed to be effective but the study had to be prematurely terminated because of thromboembolic events ${ }^{28}$ (two nonfatal myocardial infarctions were seen, perhaps as a result of CD154 expression on activated platelets).

Interference with the co-stimulatory signals might have severe unexpected side effects as shown in a Phase I trial in 2006, where an agonistic monoclonal antibody to CD28 led to a cytokine release syndrome in all healthy subjects receiving the antibody. ${ }^{29}$

\section{Calcineurin inhibitors}

Calcineurin inhibitors disrupt the activation of T-cells by reducing the production of IL-2. Cyclosporine (CsA) was first used successfully in 18 patients with refractory proliferative lupus nephritis in $1989 .{ }^{30}$ Further small retrospective studies and two randomized controlled trials in proliferative lupus nephritis (one in 40 children and the other in 75 adults) ${ }^{31,32}$ provided more evidence that $\mathrm{CsA}$ has positive therapeutic, mainly antiproteinuric, effects. Moroni et al recommended trying CsA in patients with nephrotic-range proteinuria who do not respond to standard treatment. ${ }^{30}$ Side effects, and a missing control of serological activity, may be the reason that CsA actually is not used in any ongoing Phase III trial in proliferative lupus nephritis registered in www.ClinicalTrials.gov. In patients with SLE associated membranous nephropathy, the use of CsA seems reasonable, as up to $75 \%$ of patients with idiopathic membranous nephropathy respond 
Table I New treatment approaches in patients with systemic lupus erythematosu

\begin{tabular}{|c|c|c|c|}
\hline Therapeutics & Characteristics & Effect & References \\
\hline Rituximab & Anti-CD20 mAB & Depletion of B-cells & $10-15$ \\
\hline Ocrelizumab & Anti-CD20 mAB & Depletion of B-cells & ClinicalTrials.gov \\
\hline Ofatumumab** & Anti-CD20 mAB & Depletion of B-cells & 16 \\
\hline Veltumumab** & Anti-CD20 mAB & Depletion of B-cells & 16 \\
\hline Epratuzumab & Anti-CD22 mAB & $\begin{array}{l}\text { Reduction of B-cells, } \\
\text { B cell modification }\end{array}$ & 17,18 \\
\hline Abetimus & $\begin{array}{l}\text { Four dsDNA epitopes } \\
\text { on a PEG platform }\end{array}$ & $\begin{array}{l}\text { Cross-links anti-dsDNA Ig } \\
\text { receptor, } \Downarrow \text { anti-dsDNA }\end{array}$ & 19,20 \\
\hline Belimumab & Anti-BLyS mAB & $\begin{array}{l}\text { Prevention of sBLYS } \\
\text { binding to receptor }\end{array}$ & 21,22 \\
\hline Atacicept & sTACI-receptor & $\begin{array}{l}\text { Antagonistic effect on } \\
\text { BLyS/APRIL }\end{array}$ & ClinicalTrials.gov \\
\hline Abatacept & CTLA4-Ig fusion protein & $\begin{array}{l}\text { Interaction with } \mathrm{B} 7 \Rightarrow \text { co-stimulatory } \\
\text { blockade, } \mathrm{T} \text {-cell activation inhibition }\end{array}$ & I I, 26 ClinicalTrials.gov \\
\hline Belatacept & CTLA4-Ig fusion protein & $\begin{array}{l}\text { Interaction with } \mathrm{B} 7 \Rightarrow \text { co-stimulatory } \\
\text { blockade }\end{array}$ & ClinicalTrials.gov \\
\hline IDEC-|3| & Anti-CDI54 mAB & $\begin{array}{l}\text { CD } 40 \mathrm{~L} \text { blockade } \Rightarrow \text { co-stimulatory } \\
\text { blockade }\end{array}$ & 27 \\
\hline BG9588 & Anti-CD40L mAB & $\begin{array}{l}\text { CD40L blockade } \Rightarrow \text { co-stimulatory } \\
\text { blockade }\end{array}$ & 28 \\
\hline Cyclosporine & Cyclic peptide of II amino acids & $\begin{array}{l}\text { Calcineurin inhibitor, } \Downarrow \text { T-cell } \\
\text { activation/proliferation }\end{array}$ & $30-33$ \\
\hline Tacrolimus & Macrolid & $\begin{array}{l}\text { Calcineurin inhibitor, } \Downarrow \mathrm{T} \text {-cell } \\
\text { activation/proliferation }\end{array}$ & $34-36$ \\
\hline Sirolimus & Rapamycin- mTOR inhibitor & $\begin{array}{l}\text { Blockade of T- and B- } \\
\text { cell activation to IL-2 }\end{array}$ & $37-39$ \\
\hline Infliximab & Anti-TNF mAB & Neutralization of TNF & 41 \\
\hline $\begin{array}{l}\text { Etanercept and } \\
\text { other anti-TNF biologicals }\end{array}$ & Fusion protein with part of TNF-R2 & Neutralization of TNF & 41 \\
\hline $\mathrm{B}-\mathrm{N} I 0$ & Anti-IL-IO & $\begin{array}{l}\text { Reduction of B-cell } \\
\text { proliferation }\end{array}$ & 46 \\
\hline Tocilizumab & Anti-IL-6 receptor mAB & $\begin{array}{l}\text { Inhibition of IL- } 6 \Rightarrow \text { B-cell and } \\
\text { T-cell differentiation } \Downarrow\end{array}$ & 16,48 \\
\hline Sifalimumab & Anti-human IFN- $\alpha$ mAB & Inhibition of IFN- $\alpha$ & 5I, 52 ClinicalTrials.gov \\
\hline Rontalizumab & Anti-human IFN- $\alpha$ mAB & Inhibition of IFN- $\alpha$ & ClinicalTrials.gov \\
\hline Edratide & $\begin{array}{l}\text { Synthetic peptide on CDRI } \\
\text { of pathogenic anti-DNA mAB }\end{array}$ & $\begin{array}{l}\text { Downregulation of pro- } \\
\text { inflammatory cytokines, pro- } \\
\text { apoptotic molecules }\end{array}$ & 53 ClinicalTrials.gov \\
\hline Eculizumab & Anti-C5b mAB & $\begin{array}{l}\text { Blockade of terminal } \\
\text { complement activation }\end{array}$ & 54 \\
\hline
\end{tabular}

Notes: **denotes treatments not used in SLE yet.

Abbreviations: MHC, major histocompatiability complex; CsA, cyclosporin A; IL-2, interleukin-2; mAb, monocloral antibodies; IFN, interferon; TNF, tumor necrosis factor; BAFF, B-cell activating factor; BLyS, B lymphocyte stimulator.

to this treatment. Small-sized retrospective studies showed positive results. ${ }^{30}$ Recently a randomized, controlled trial showed that CsA or intravenous cyclophosphamide pulses were both more effective than prednisone alone, but relapses of the nephrotic syndrome occurred significantly more often after completion of CsA than after intravenous cyclophosphamide..$^{33}$ The role of CsA needs to be better defined especially with regard to relapses after termination, the risk of nephrotoxicity, and other side-effects that might reduce patient adherence over a prolonged treatment period.
Tacrolimus, another calcineurin inhibitor, has been reported to be successful in patients with refractory lupus, and mainly in patients with lupus nephritis. ${ }^{34}$ Having a high T-cell suppressive activity, and no gingival hypertrophy or hypertrichosis, tacrolimus has advantages compared to CsA, but the risk of diabetes or neurological adverse effects have to be taken into account. The positive results of tacrolimus have been supported recently. In an open labelled pilot study, tacrolimus (20 patients) was compared with intravenous cyclophosphamide treatment (18 patients) in active lupus 
nephritis. Tacrolimus was more effective in improving proteinuria and inhibiting anti-dsDNA antibody production with a reduced incidence of pulmonary infections. ${ }^{35}$ Another small study with a total of 60 patients showed comparable efficacy of MMF, tacrolimus, and intravenous cyclophosphamide in lupus nephritis regarding complete remission. ${ }^{36}$ Phase III trials with tacrolimus or a combination of tacrolimus and MMF have already been completed or are recruiting (www. ClinicalTrials.gov) and results should be available soon.

\section{Other inhibitors}

Sirolimus (also known as rapamycin), a newer immunosuppressive drug, inhibits the mammalian target of rapamycin (mTOR) pathway with the result of a blockade of T- and B-cell activation to IL-2. Used in many transplant patients, there is a limited use in SLE patients despite the fact the mTOR seems to be an imported mediator in SLE. ${ }^{37,38}$ A prospective Phase II trial of sirolimus for the treatment of SLE is recruiting patients. In patients with lupus nephritis, a number of side effects, and especially the development of proteinuria seen in transplant recipients, has to be taken into account. ${ }^{39}$

\section{Anti-cytokine approach}

As cytokine dysregulation can be demonstrated in mouse models and in patients with SLE, an anticytokine approach seems promising in this autoimmune disease. IL-1 and TNF- $\alpha$ are the most important cytokines in many inflammatory conditions. However, IL-1 receptor antagonists have not shown to improve murine lupus nephritis. ${ }^{40}$ Data of anti-TNF therapy in patients with SLE are sparse and consist mainly of case reports. The most widely used anti-TNF- $\alpha$ antibody is infliximab (Remicade; Centocor Ortho Biotech Horsham, PA), a chimeric monoclonal antibody which given intravenously blocks TNF- $\alpha$. In six refractory SLE patients, a significant improvement was seen but relapses occurred in arthritis after anti-TNF therapy was stopped. ${ }^{41}$ Other anti-TNF biologicals are available and might be used. However, TNF inhibitorrelated lupus has been reported ${ }^{42,43}$ and safety concerns regarding long-term application, which would probably be necessary for lupus arthritis, may limit the use. Despite a very promising report on a low rate of severe adverse events in a large group of patients with psoriatic arthritis and a total follow-up of 1776 person-years, ${ }^{44}$ the risk of severe infections cannot be denied, especially for intracellular organisms, and an increased rate of urinary tract infections as well as cases of pneumonia have been reported. ${ }^{41}$ (we have observed a life-threatening peritonitis in a young male patient treated with a single dose).
Elevated IL-10 production by monocytes and B-cells could be demonstrated in SLE. IL-10 is involved in B-cell proliferation and anti-IL10 therapy delays the onset of autoimmunity in murine lupus. ${ }^{45}$ Monoclonal anti-IL-10 antibodies have been given to six patients with SLE leading to a rapid improvement of arthritis, skin manifestations, and constitutional symptoms. ${ }^{46}$

IL-6 is an important proinflammatory cytokine inducing for example B-cell and T-cell differentiation. Anti-IL-6 antibodies in a murine lupus model prolonged survival and reduced kidney disease. ${ }^{47}$ In a Phase I study, 16 patients with mild to moderate manifestations received tocilizumab, a humanized monoclonal antibody directed to the IL-6 receptor. ${ }^{16}$ It was well tolerated and the disease scores improved. ${ }^{48}$ However neutropenia may limit the maximum dosage.

IFN- $\alpha$ seems to play a significant role in SLE. IFN levels were found elevated in patients, correlating with disease activity, ${ }^{49}$ and gene expression profiles in mononuclear cells of SLE patients showed a cluster of genes modulated by IFN. ${ }^{50}$ In a Phase I study anti-IFN- $\alpha$ monoclonal antibody neutralized over-expression of IFN- $\alpha /$ - $\beta$-inducible genes, ${ }^{51}$ and in a Phase I/II trial the anti-human IFN- $\alpha$ antibody (fully human monoclonal antibody, MEDI-545) led to a significant improvement and reduced relapse rate in patients with skin manifestations. ${ }^{52}$ A study to evaluate the long-term safety of MEDI-545 (sifalimumab) has not yet been opened (www.ClinicalTrials.gov), and a Phase II trial for the use of another anti-IFN- $\alpha$ monoclonal antibody (rontalizumab) in moderately to severely active lupus patients is recruiting.

\section{Other therapeutic approaches} Edratide

Edratide (hCDR1), a tolerogenic peptide leading to a downregulation of proinflammatory cytokines (IL-1 $\beta$, TNF- $\alpha$, IFN- $\gamma$, IL-10, and BLyS) and to a downregulation of pro-apoptotic molecules (caspase-3 and caspase-8) and an upregulation of the immunosuppressive cytokine TGF-beta and FoxP3 in five patients with SLE, seems to be a promising new drug. ${ }^{53}$ However, in a Phase II trial with edratide in SLE patients with moderately active disease, the primary endpoints (improvement of disease activity score and steroid tapering) were not met (www.ClinicalTrials.gov).

\section{Eculizumab (anti-C5b)}

In patients with SLE, the deposition of immune complexes leads to an activation of the complement system, amplifying the inflammatory response. Activation of the terminal 
complement complex is associated with disease reactivation, whereas on the other hand, complement factors are important for the clearance of immune complexes. Eculizumab, a monoclonal antibody targeting the $\mathrm{C} 5$ complement protein and blocking its cleavage, has given promising results in mice and in a Phase I trial. ${ }^{54}$

\section{Stem cell transplantation}

Autologous hematopoietic stem cell transplantation has been used in a limited number of patients in refractory life-threatening manifestations. Beside the possibility of an ultra-high immunosuppressive treatment, it gives the chance of an immunological reconstitution hopefully leading to tolerance. Promising results have been reported in small patient groups, ${ }^{55,56}$ and prospective trials will have to show the efficacy and toxicity in comparison to the conventional and new treatment possibilities.

Positive results of mesenchymal stem cell transplantation have been reported in four Chinese patients refractory to cyclophosphamide and steroid treatment. ${ }^{57}$

\section{"Pseudoviral immunity"}

Recently a "pseudoviral immunity" in SLE patients has been proposed as a novel pathogenetic disease concept. ${ }^{58}$ Chromatin and ribonucleoprotein particles resemble viral particles and have a similar potency to trigger nucleic acid sensors of the innate immune system, and to lead to antigen-specific B and T-cell responses. This may offer novel targets for therapy; for example the Toll-like receptor pathways. In experimental lupus nephritis, blockade of TLR9 with specific G-rich DNAoligonucleotids suppresses lupus activity. ${ }^{59}$ A clinical Phase I trial has been completed where the investigators hypothesize that statin drugs (such as atorvastatin) slow the progression of SLE by down regulation of Toll-like receptors 2, 4 and 9 pathways (www.ClinicalTrials.gov).

\section{Other}

Other therapeutic targets are proposed from studies in lupus patients and animal models. Accumulating evidence has shown the important role of chemokines and chemokine receptors in murine lupus models; ${ }^{60}$ findings that may be applicable to treatment in humans. Recently, elevated levels of angiopoietin-2 facilitating vascular inflammation in SLE have been shown. ${ }^{61}$ Strategies to control the deleterious effects of angiopoietin-2 may open new perspectives to prevent endothelial inflammation in SLE, as the therapeutic efficacy of selective angiopoetin-2 blockade has already been demonstrated in murine models with pathologic angiogenesis. ${ }^{61}$

\section{Conclusion}

Besides all the approaching new treatment options the initial excitement of many groups has been disappointed by negative results from large randomized controlled trials. There are different explanations for this phenomenon, everyone of them probably containing a part of the truth. One is a very high background treatment in patients with only moderate severe SLE where a monoclonal antibody is added. The added treatment might not have the chance to show its effectiveness. A second, very important point, is that SLE is a heterogeneous disease and large multicenter trials probably have to take this into account and differentiate between subgroups not only by stratification. Studies on a more individualized treatment regarding gender and ethnicity are needed. With regard to the worse prognosis of male patients, and the more severe disease in African and Hispanic patients with the renal involvement in up to $60 \%$ of the patients progressing to end-stage renal failure, it would appear that different therapeutic approaches may be needed in different groups. ${ }^{62}$ In addition, different organ involvement may need different treatment approaches that may not be reflected by the activity score alone. The same is true for patients at different stages: first manifestations probably have to be treated differently than relapses, and rescue treatment might involve protocols and drugs that might not be used as first line approach. Taking these arguments into account, and the fact that positive long-term results need long-term follow-up of at least 5 years, there is a real need for effective markers in regard to prognosis, treatment response, and the risk of side effects.

\section{Disclosure}

The author has taken part in the ALMS trial (Aspreva) and is principal investigator for Germany in the BELONG Study (Roche). The author has received honoraria for traveling and lectures from Aspreva and Roche.

\section{References}

1. Trager J, Ward MM. Mortality and causes of death in systemic lupus erythematosus. Curr Opin Rheumatol. 2001;13:345-351.

2. Abu-Shakra M, Urowitz MB, Gladman DD, Gough J. Mortality studies in systemic lupus erythematosus. Results from a single center. II. Predictor variables for mortality. J Rheumatol. 1995;22: 1265-1270.

3. Jacobsen S, Petersen J, Ullman S, et al. Mortality and causes of death of 513 Danish patients with systemic lupus erythematosus. Scand J Rheumatol. 1999;28:75-80.

4. Korbet SM, Lewis EJ, Schwartz MM, et al; for Lupus Nephritis Collaborative Study Group. Factors predictive of outcome in severe lupus nephritis. Am J Kidney Dis. 2000;35:904-914.

5. Moroni G, Quaglini A, Maccario M, Banfi G, Ponticelli C. "Nephritic flares" are predictors of bad long-term renal outcome in lupus nephritis. Kidney Int. 1996;50:2047-2053. 
6. Chan TM, Li FK, Tang CS, et al; for Hong Kong-Guangzhou Nephrology Study Group. Efficacy of mycophenolate mofetil in patients with diffuse proliferative lupus nephritis. $N$ Engl J Med. 2000;343: $1156-1162$.

7. Ginzler EM, Dooley MA, Aranow C, et al. Mycophenolate mofetil or intravenous cyclophosphamide for lupus nephritis. $N$ Engl J Med. 2005;353:2219-2228.

8. Appel GB, Contreras G, Dooley MA, et al. Mycophenolate mofetil versus cyclophosphamide for induction treatment of lupus nephritis. J Am Soc Nephrol. 2009;20:1103-1112.

9. Haubitz M. Acute and long-term toxicity of cyclophosphamide. Transplantationsmedizin. 2007;19:26-31.

10. Edwards JC, Szczepanski L, Szechinski J, et al. Efficacy of B-celltargeted therapy with rutuximab in patients with rheumatoid arthritis. N Engl J Med. 2004;350:2572-2581.

11. Bhat P, Radhakrishnan J. B lymphocytes and lupus nephritis: new insights into pathogenesis and targeted therapies. Kidney Int. 2008; 73:261-268

12. Merrill JT, Neuwelt CM, Wallace DJ, et al. Efficacy and safety of rituximab in moderately-to-severely active systemic lupus erythematosus. Arthritis Rheum. 2010;62:222-233.

13. Furie R, Looney RJ, Rovin B, et al. Efficacy and safety of rituximab in subjects with active proliferative lupus nephritis: results from the randomized, double-blind Phase III LUNAR Study. Arthritis Rheum. 2009;60 Suppl 10:1149.

14. Lu TYT, Ng KP, Combrodge G, et al. A retrospective seven-year analysis of the use of B cell depletion therapy in systemic lupus erythematosus at university college London hospital: the first fifty patients. Arthritis Rheum. 2009;61:482-487.

15. Lapsiwala A, Parhizgar A, Ghahramani N. A systematic review and meta-analysis of rituximab in refractory lupus nephritis. Am Soc of Nephrol. 2009; Abstract F-PO 1289.

16. Robak E, Robak T. Monoclonal antibodies in the treatment of systemic lupus erythematosus. Curr Drug Target. 2009;10:26-37.

17. Dörner T, Kaufmann J, Wegener WA, Teoh N, Goldenberg DM, Burmester GR. Initial clinical trial of epratuzumab (humanized antiCD22 antibody) for immunotherapy of systemic lupus erythematosus. Arthritis Res Ther. 2006;8:1-11.

18. Wallace D, Hobbs K, Houssiau F, et al. Randomized controlled trials of epratuzumab (anti-CD22 mab targeting B-cells) reveal clinically meaningful reductions in corticosteroid use with favourable safety profile in moderate and severe flaring SLE patients. Ann Rheum Dis. 2008;67 Suppl 2:S212.

19. Alarcon-Segovia D, Tumlin JA, Furie RA,et al. LJP 394 for the prevention of renal flare in patients with systemic lups erythematosus: results from a randomized, double-blind, placebo-controlled study. Arthritis Rheum. 2003;48:442-454

20. Horowitz DM, Furie RA. Abetimus sodium: a medication for the prevention of lupus nephritis flares. Expert Opin Pharmacother. 2009;10:1501-1507.

21. Jacobi AM, Huang W, Wang T, et al. Effect of long-term belimumab treatment on B-cells in systemic lupus erythematosus. Arthritis Rheum. 2010;62:201-210

22. Wallace DJ, Stohl W, Furie RA, et al. A phase II randomized, doubleblind, placebo-controlled, dose-ranging study of belimumbab in patients with active systemic lupus erythematosus. Arthritis Rheum. 2009;61:1168-1178.

23. Navarra S, Guzman R, Gallacher A, et al. Belimumab, a BLyS-specific inhibitor, reduced disease activity, flares and prednisone use in patients with active SLE: efficacy and safety results from the Phase 3 BLISS-52 study. American College of Rheumatology 2009, Abstract LB1.

24. Zhou YB, Ye RG, Li YJ, Xie CM, Wu YH. Effect of anti-CD134L mAb and CTLA4Ig on ConA-induced proliferation, Th cytokine secretion, and anti-dsDNA antibody production in spleen cells from lupus-prone BXSB mice. Autoimmunity. 2008;41:395-404.
25. Schiffer L, Sinha J, Wang X, et al. Short term administration of costimulatory blockade and cyclophosphamide induces remission of systemic lupus erythematosus nephritis in NZB/W F1 mice by a mechanism downstream of renal immune complex deposition. $J$ Immunol. 2003;171:489-497.

26. Merrill JT, Burgos-Vargas R, Westhovens R, et al. Activity of abatacept in SLE: results of a 12-month phase II exploratory study. Ann Rheum Dis. 2009;68 Suppl 3:S70.

27. Kalunian KC, Davis JC Jr, Merrill JT, et al. Treatment of systemic lupus erythematosus by inhibition of T-cell costimulation with anti-CD154: a randomized, double-blind, placebo-controlled trial. Arthritis Rheum. 2002;46:3251-3258.

28. Boumpas DT, Furie R, Manzi S, et al. A short course of BG9588 (anti-CD40 ligand antibody) improves serologic activity and decreases hematuria in patients with proliferative lupus glomerulonephritis. Arthritis Rheum. 2003;48:719-727.

29. Suntharalingam G, Perry MR, Ward S, et al. Cytokine storm in a phase I trial of the anti-CD28 monoclonal antibody TGN1312. N Engl J Med. 2006;355:1018-1028.

30. Moroni G, Doria A, Ponticelli C. Cyclosporine A in lupus nephritis: assessing the evidence. Nephrol Dial Transplant. 2009;24:15-20.

31. Fu LW, Yang LY, Chen WP, et al. Clinical efficacy of cyclosporin a neoral in the treatment of paediatric lupus nephritis with heavy proteinuria. Br J Rheumatol. 1998;37:217-221.

32. Moroni G, Doria A, Mosca M, et al. A randomized pilot trial comparing cyclosporine versus azathioprine for maintenance therapy in diffuse lupus nephritis over four years. Clin J Am Soc Nephrol. 2006;1:925-932.

33. Austin HA, Illei GG, Braun MF, Balow JE. Randomized, controlled trial of prednisone, cyclophosphamide, and cyclosporine in lupus membranous nephropathy. J Am Soc Nephrol. 2009;20:901-911.

34. Mok CC, Tong KH, To CH, et al. Tacrolimus for induction therapy of diffuse proliferative lupus nephritis: an open-labeled pilot study. Kidney Int. 2005;68:813-817.

35. Qu L, Wang S, Chen J. Clinical analysis of tacrolimus therapy versus intermittent cyclophosphamide pulse treatment in lupus nephritis. American Society of Nephrology. 2009; PO237:Abstract.

36. Li X, Ren H, Zhang W, et al. Induction therapies for proliferative lupus nephritis: mycophenolate mofetil, tacrolimus and intravenous cyclophosphamide. American Society of Nephrology. 2009; PO1221:Abstract.

37. Fernandez D, Bonilla E, Mirza N, Niland B, Perl A. Rapamycin reduces disease activity and normalizes T-cell activation-induced calcium fluxing in patients with systemic lupus erythematosus. Arthritis Rheum. 2006;54:2983-2988.

38. Medina F, Fuentes J, Carranza I, et al. Sirolimus: a potential treatment for diffuse proliferative lupus nephritis. Ann Rheum Dis. 2006;65:351.

39. Merkel S, Mogilevskaja N, Mengel M, Haller H, Schwarz A. Side effects of sirolimus. Transplant Proc. 2006;38:714-715.

40. Kiberd BA, Stadnyk AW. Established murine lupus nephritis does not respond to exogenous interleukin-1 receptor antagonist; a role for the endogenous molecule? Immunopharmacology. 1995;30:131-137.

41. Aringer M, Smolen JS. TNF inhibition in SLE: where do we stand? Lupus. 2009;18:5-8.

42. Neradova A, Stam F, van den Berg JG, Bax WA. Etanercept-associated SLE with lupus nephritis. Lupus. 2009;18:667-668.

43. Luong JM, Tan BT, Buchanan RR, Schachna L. Tumour necrosis factor inhibitor-related lupus: safety of switching agents. Clin Rheumatol. 2010;29:551-553.

44. Saad AA, Ashcroft DM, Watson KD, Symmons DPM, Noyce PR, Hyrich KL. Efficacy and safety of anti-TNF therapies in psoriatic arthritis: an observational study from the British Society for Rheumatology Biologics Register. Rheumatology. 2010;49:697-705.

45. Ishida $\mathrm{H}$, Muchamuel $\mathrm{T}$, Sakaguchi $\mathrm{S}$, et al. Continuous administration of anti-interleukin 10 antibodies delays onset of autoimmunity in NZB/ WF1 mice. J Exp Med. 1994;179:305-310. 
46. Llorente L, Richaud-Patin Y, Garcia-Padilla C, et al. Clinical and biological effects of anti-IL-10 monoclonal antibody administration in systemic lupus erythematosus. Arthritis Rheum. 200;43:1790-1800.

47. Mihara M, Takagi N, Takeda Y, Ohsugi Y. IL-6 receptor blockage inhibits the onset of autoimmune kidney disease in NZB/W F1 mice. Clin Exp Immunol. 1998;112:397-402.

48. Illei GG, Shirota Y, Yarboro $\mathrm{CH}$, et al. Tocilizumab in systemic lupus erythematosus: data on safety, preliminary efficacy, and impact on circulating plasma cells from an open-label phase I dosage-escalation study. Arthritis Rheum. 2010;62:542-552.

49. Rönnblam 1, Eloranta ML, Alm GV. The type I interferon system in systemic lupus erythematosus. Arthritis Rheum. 2006;54:408-420.

50. Baechler EC, Batliwalla FM, Karypis G, et al. Interferon-inducible gene expression signature in peripheral blood cells of patients with severe lupus. Proc Natl Acad Sci U S A. 2003;100:2610-2615.

51. Yao Y, Richman L, Higgs BW, et al. Neutralization of interferon-alpha/ beta-inducible genes and downstream effect in a phase I trial of an antiinterferon-alpha monoclonal antibody in systemic lupus erythematosus. Arthritis Rheum. 2009;60:1785-1796.

52. Wallace DJ, Petri MA, Olsen M et al. MEDI-545, an anti-interferon alpha monoclonal antibody, shows evidence of clinical activity in systemic lupus erythematosus. Arthritis Rheum. 2007;56:526-527

53. Sthoeger ZM, Sharabi A, Molad Y, et al. Treatment of lupus patients with a tolerogenic peptide, hCDR1 (Edratide). Immunomodulation of gene expression. Hum Immunol. 2009;33:77-82.

54. Furie R, Matis L, Rolins S, et al. A single dose, placebo-controlled, double blind, phase I study of the humanized anti-C5 antibody hbG1 in patients with systemic lupus erythematosus. American College of Rheumatology. 2004; Abstract.
55. Burt RK, Traynor A, Statkute L, et al. Nonmyeloablative hematopoietic stem cell transplantation for systemic lupus erythematosus. JAMA. 2006;295:527-535.

56. Farge D, Labopin M, Tyndall A, et al. Autologous hematopoietic stem cell transplantation for autoimmune diseases: an observational study on 12 years of experience from the european group for blood and marrow transplantation working party on autoimmune diseases. Haematologica. 2010;95:284-292.

57. Sun L, Akiyama K, Zhang H, et al. Mesenchymal stem cell transplantation reverses multiorgan dysfunction in systemic lupus erythematosus mice and humans. Stem Cells. 2009;27:1421-1432.

58. Anders HJ. Pseudoviral immunity - a novel concept for lupus. Trends Mol Med. 2009;15:553-561.

59. Patole PS, Zecher D, Pawar Rd, Gröne Hjk, Schlöndorff D, Anders HJ G-rich DNA suppresses systemic lupus. J Am Soc Nephrol. 2005;16: 3273-3280.

60. Hasegawa H. Chemokine blockade for lupus model mice. Front Biosci. 2008;13:2900-2908.

61. Kümpers P, David S, Haubitz M, et al. The Tie2 receptor antagonist angiopoietin2 facilitates vascular inflammation in systemic lupus erythematosus. Ann Rheum Dis. 2009;68:1638-1643.

62. Haubitz M. Is individualized therapy the future of lupus treatment? Future Rheumatol. 2008;3:143-151.
Biologics: Targets \& Therapy

\section{Publish your work in this journal}

Biologics: Targets \& Therapy is an international, peer-reviewed journal focusing on the patho-physiological rationale for and clinical application of Biologic agents in the management of autoimmune diseases, cancers or other pathologies where a molecular target can be identified. This journal is indexed on PubMed Central, CAS, EMBase, Scopus

\section{Dovepress}

and the Elsevier Bibliographic databases. The manuscript management system is completely online and includes a very quick and fair peerreview system, which is all easy to use. Visit http://www.dovepress. $\mathrm{com} /$ testimonials.php to read real quotes from published authors. 